\section{LEARN AT YOUR OWN PACE}

Healthcare Learning: Smile-on and Plymouth University Peninsula Schools of Medicine \&t Dentistry bring you the first online postgraduate MSc in Healthcare Strategy \& Performance.

Designed for both clinical and non-clinical healthcare professionals, the two-year course looks at key principles of business and how these apply to you as a healthcare provider, covering areas such as: Management and Leadership, Entrepreneurship, Healthcare Administration, Strategic Project Management, and International Healthcare Policy.

Delivered through a mixture of webinars, face-to-face tuition and online resources, the course even enables you continue with all your current working and personal commitments, as you can learn at a pace that suits you.

If you are looking to develop your skills and take the next step in your career, find out more about the MSc in Healthcare Strategy \&t Performance from Healthcare Learning: Smile-on today.

To find out more, email info@ healthcare-learning.com or call 02074008989.

\section{A HOST OF ENGAGING WEBINARS}

Enrolling at the DENTSPLY Academy is one of the simplest ways to earn verifiable CPD and it's completely free. Every month DENTSPLY Academy runs a host of engaging and informative webinars.

In September Dr Mike

Horrocks will be presenting

'Modern Management of

Dental Traumatology', looking at techniques for managing incomplete root formation as well as evaluating contemporary management of dental trauma.

www.dentsplyacademy.co.uk

\section{TESTING AND VALIDATION EQUIPMENT}

Infection control specialists Dentisan have launched a full range of testing and validation equipment, providing all the tests a practice needs to fully audit the performance of washer disinfectors, ultrasonic cleaners and autoclaves on a daily, weekly and quarterly basis.

Distributed via Henry Schein Dental, the new range includes the Bowie Dick Green Card Test, which effectively checks the stream penetration in an autoclave; the Wash Checks and Holder, which monitors the effectiveness of the wash process in washer disinfectors and clearly identifies if there are problems within the cleaning process; the Protein Residue Test, which detects residual proteins left on the surfaces of dental and surgical instruments; the Helix Device - a heli-check hollow load Process Challenge Device, with disposable chemical indicator strips, which tests steam penetration in autoclaves; and Class 4, 5 and 6 Indicators which ensures correct sterilisation conditions have reached the wrapped instruments.

Dentisan's testing and validation products are available from Henry Schein Dental: call 08700102043 or visit www. henryschein.co.uk.

\title{
PROPER, APPROPRIATE HANDPIECE MAINTENANCE
}

Proper and appropriate handpiece maintenance is incredibly important to get the best out of your equipment. Bien-Air supply a range of maintenance products to help you and have recently reduced the prices to make them even more affordable: Lubrimed - Medical Grease Cartridges supplied in a box of six refills, enough for approximately 330 applications, recommended for Bien-Air high speed turbines (£18.00 + VAT); Lubrifluid - Lubricant supplied in $500 \mathrm{ml}$ can complete with nozzles, developed for contra-angled, straight handpieces, air motors and turbines (£25 + VAT per can); Spraynet - Disinfectant Cleaning Spray supplied in 500 $\mathrm{ml}$ can complete with nozzles ( $£ 25$ per can); and Aquacare - Cleaner specifically designed to dissolve physiological fluids such as saline, recommended for implantology handpieces (£20 + VAT per $500 \mathrm{ml}$ can).

\section{FREE CPD FOR DENTAL PROFESSIONALS}

Dentalcare.com is Oral-B's online resource which now offers ten CPD courses, most of which have been accredited by the British Society of Dental Hygiene and Therapy (BSDHT). Alternatively, you may like to relax and listen to a selection of prerecorded webinars, given by leaders in their field, including Professors Crispian Scully and Jack Toumba, and Dr Louis MacKenzie.

The courses cover a variety of topics from motivational interviewing to diagnosis of oral mucosal lesions. All courses are free and provide between one and four hours of verifiable CPD. Using the modules is easy. Simply click on the course in
When working out your costings don't overlook the fact that all Bien-Air maintenance product cans are $500 \mathrm{ml}$ and that the nozzles are included in the price! Call Bien-Air directly on 01293 550200.

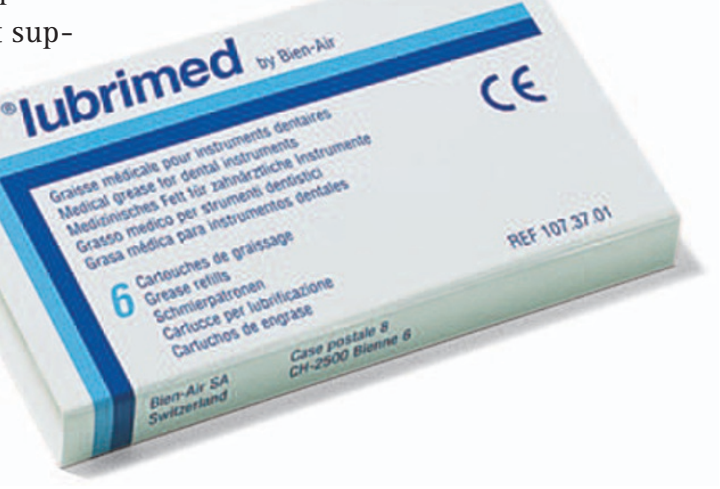

